\title{
Control of Induction Motors by Using Programmable Logic Controllers (PLC)
}

\author{
Awadallah Sulieman Rahama ${ }^{1}$, Dr. Dalia Mahmoud ${ }^{2}$ \\ ${ }^{1,2}$ Department of Control, Faculty of Engineering, Al Neelain University, Khartoum, Sudan, 2016
}

\begin{abstract}
Automation is the process of handling various parameters of process like flow, temperature, etc. without presence of responsible person. Where classic control there is difficulty in maintenance therefore, use programmable logic controllers (PLC) to solve these problems. In the development of automation controllers the trend has been to move towards soft controllers so as to provide better control, more flexibility and more reliability with intelligent diagnostics of machine faults and so industries have gradually moved from conventional relay logic control to programmable logic controller $(P L C)$ and three phase squirrel cage induction motors are widely used motors in industry and the implementation of monitoring and control system for the induction motor based on programmable logic controller technology is described. Also the implementation of a hardware and software for speed control and protection with the result obtained from the test on induction motor performance is provided and this idea presents a design and implementation of a monitoring and control system for the three phase induction motor based on programmable logic controller (PLC) technology and the programmable logic controller $(P L C)$ correlates the operational parameters to the speed requested by the user and monitors the system during normal operation and under trip conditions. Thus, programmable logic controller (PLC) proves an effective tool in industrial control of electric drives.
\end{abstract}

Keywords: PLC, Ladder, fluids.

\section{Introduction}

Since technology for motion control of electric drives became available, the use of programmable logic controllers (PLCs) with power electronics in electric machines applications has been introduced in the manufacturing automation [1]. AC induction motors are used as actuators in many industrial processes. Although induction motors are reliable, they are subjected to some undesirable stresses, causing faults resulting in failure. Monitoring of an induction motor is a fast emerging technology for the detection of initial faults. It avoids unexpected failure of an industrial process. Monitoring techniques can be classified as the conventional and the digital techniques. Classical monitoring techniques for three phase induction motors are generally provided by some combination of mechanical and electrical monitoring equipment. Mechanical forms of motor sensing are also limited in ability to detect electrical faults, such as stator insulation failures. In addition, the mechanical parts of the equipment can cause problems in the course of operation and can reduce the life and efficiency of a system [4]. Almost any production line, machine function or process can be automated using a PLC and the speed and accuracy of the operation can be greatly enhanced using this type of control system. But the biggest benefit in using a PLC is the ability to change and replicate the operation or process while collecting and communicating vital information. Since there were problems related to large electrical panels with a number of electrical components and extensive wiring, people felt the need for software logic controllers, so they gave birth to Programmable Logic Controller (PLC) wherein the control logic is developed in ladder diagram, a software logic control, with a number of inputs taken from the environment and generating the outputs, depending on the logic programmed, to the environment. This helped to control any machine sequence with small electrical panels, less number of electrical components and less wiring with more flexibility to change machine sequence [3]. Induction motors are used in many industrial applications in a wide range of operating areas as they have simple and robust structure, and low production costs. Induction motors are now being used more as compared to before due to their certain advantages such as versatility, dependability and economy, good self starting capability, offers users simple, rugged construction easy maintenance, low cost and reliability. The reliability of an induction motor is of great Importance in industrial as well as commercial, aerospace and military applications. Also the knowledge about fault mode behavior of an induction motor drive system is extremely important from the standpoint of improved system design, protection, and fault tolerant control. There are various methods for fault detection and protection of induction motors and some of them are on line fault detection, Stator fault monitoring techniques, Programmable Logic Controller (PLC) based protection system and in this study, the method used is PLC based protection system of induction motors. With the advent of technology and availability of motion control of electric drives, the application of Programmable Logic Controllers (PLC) with power electronics in electrical machines has been introduced in the manufacturing automation systems [5].

\section{Programmable Logic Controllers}

A PLC or a programmable logic controller is a small computer used for automation of real world processes, such as control of machinery on factory assembly lines. A programmable logic controller (PLC) can be programmed to sense, activate, and control industrial equipment. Therefore, a PLC incorporates a number of $\mathrm{I} / \mathrm{O}$ points, which allow electrical signals to be interfaced. Input and output components of the processes are connected to the PLC; and the control program is loaded on the PLC memory [2]. In this application, it controls through analog and digital inputs and outputs the varying load-constant speed operation of an induction motor and also, the PLC continuously monitors the 


\section{International Journal of Science and Research (IJSR) \\ ISSN (Online): 2319-7064 \\ Index Copernicus Value (2013): 6.14 | Impact Factor (2015): 6.391}

inputs and activates the outputs according to the control program. This PLC system is of modular type composed of specific hardware building blocks (modules), which plug directly into a proprietary bus: a central processor unit (CPU), a power supply unit, input and output modules I/O and a program terminal [3]. Such a modular approach has the advantage that the initial configuration can be expanded for other future applications and the basic structure of the PLC is illustrated in Fig. 1.

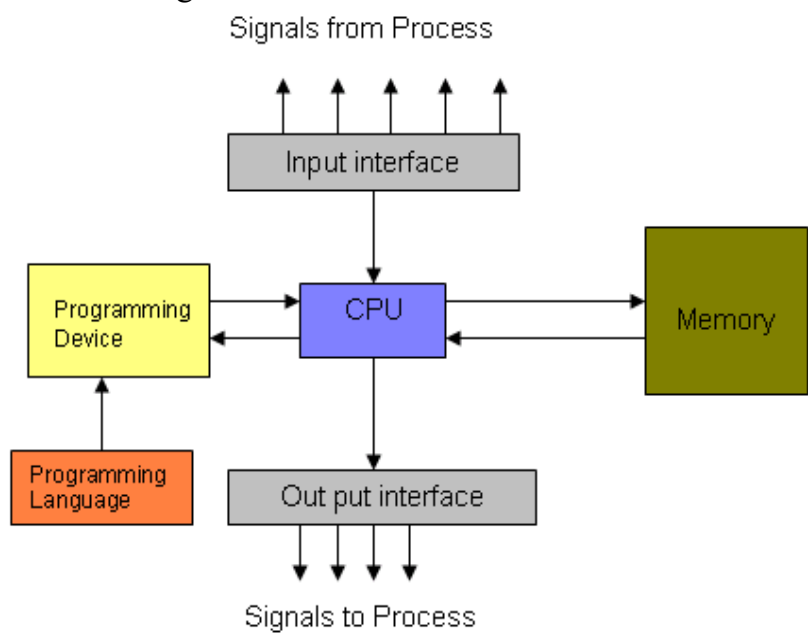

Figure 1: parts of PLC

\section{Materials and Methods}

The main objective of the work is use a programmable logic controller (PLC) instead of the classic control to make a cheap and reliable protection system for three phase induction motor and the protection system should protect the motor from voltage unbalancing, single phasing, under voltage, over voltage and thermal protection. In the past an engineers had been designing the engineering systems that require a lot of hardware. It is merely impossible to design distance control of the system as more hardware and wiring were needed. With the rise of the technology, programmable logic controller (PLC) have eased the engineering design and lessen materials required, it is because the entire design is implemented in software programming paradigm [6].

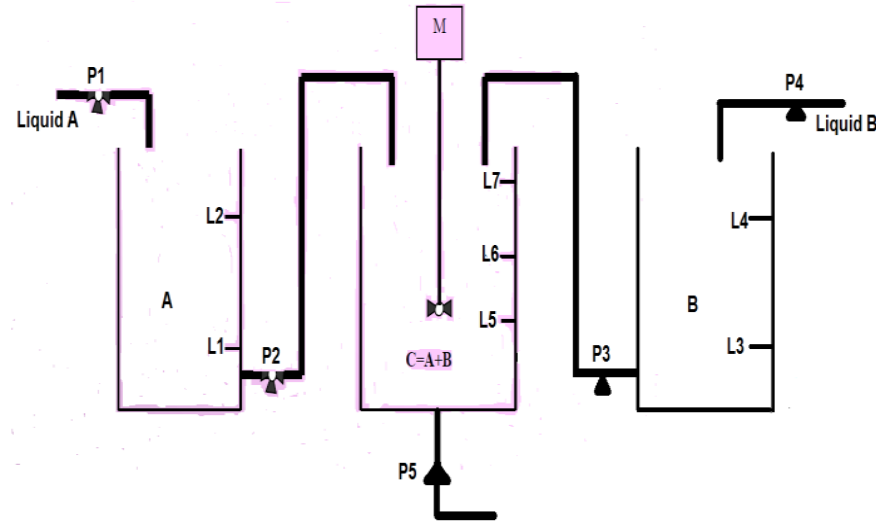

Figure 2: Elementary diagram of tank process

This project consists of three tanks and five pumps where these induction motors control in these pumps, and seven sensors and mixer for mixing the fluids. This project works when the fluid level in the first pump less than L1 and it stops when the fluid level up to L2 and operates the fourth pump when the fluid level less than L3 and it stops when the fluid level up to L4 and operates the second pump when the fluid level is less than L5 and it stops when the fluid level up to L6 and operates the third pump when the fluid level at L6 and it stops when a level of liquids up to L7 and when the fluid level up at L7 when the mixer works for a specific period of time and then stop and then operate the pump fifth straight.

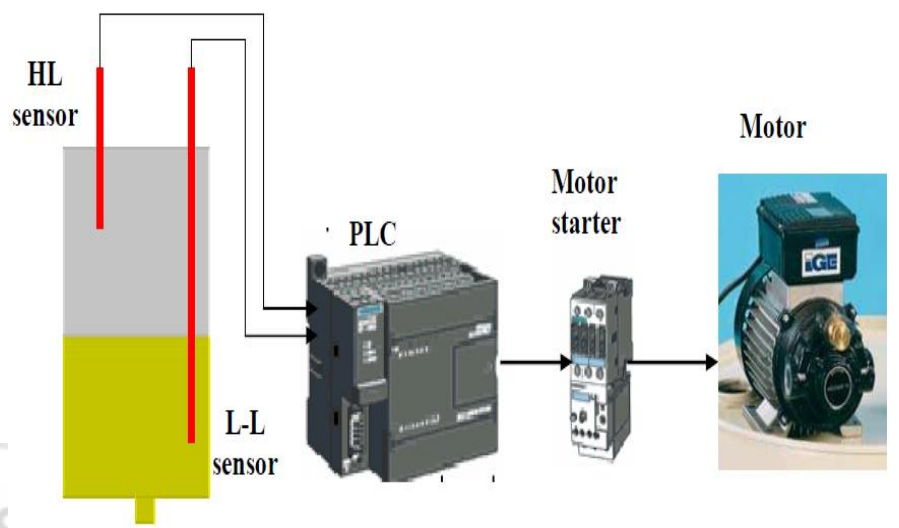

Figure 3: like first pump and fourth pump

This figure (3) is similar to the work of the first pump (P1) and the fourth pump (P4). In this figure (3) we want the fill motor to pump fluids into the tank until the high level sensor turns on. At that point we want to turn off the motor until the level falls below the low level sensor. Then we should turn on the fill motor and repeat the process.

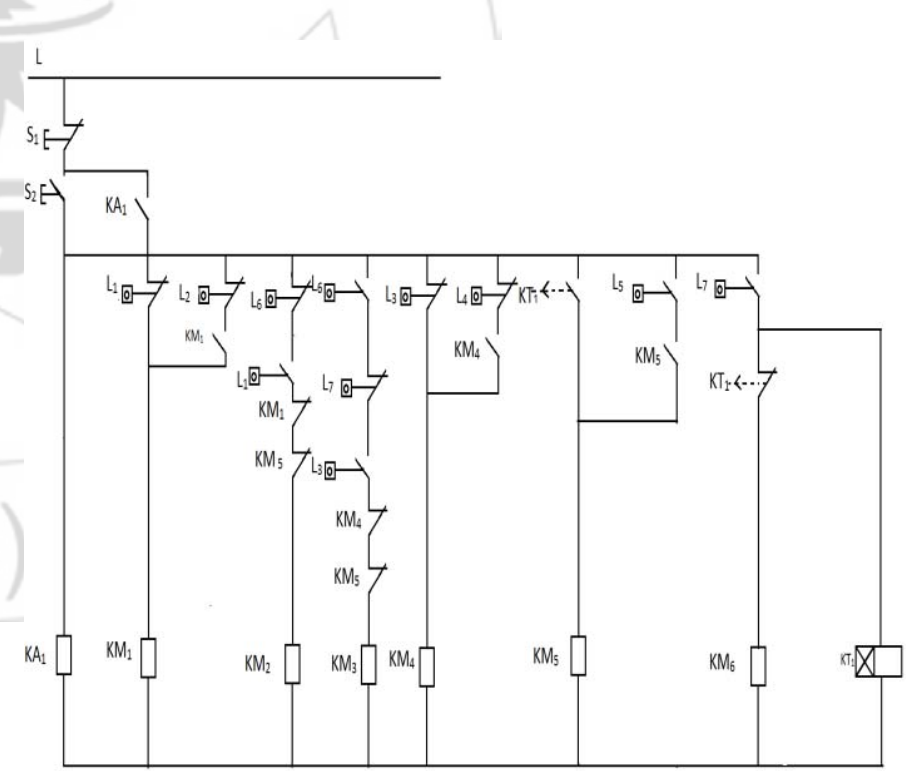

Figure 4: classic control circuit

This figure (4) illustrates the classic control circuit which consists of six contactors (KM) and one relay (KA) and timer (KT) and start pushbutton and stop pushbutton and seven level liquid switches (L) where classic control circuits are difficult maintenance and there are a large amount of wires which are difficult to detect faults easily and therefore has been the use of programmable logic controllers (PLC) in this project instead of the classic control circuit and this circuit has been converted to ladder language as shown in the figure (5) below. 


\section{International Journal of Science and Research (IJSR) \\ ISSN (Online): 2319-7064}

Index Copernicus Value (2013): 6.14 | Impact Factor (2015): 6.391

Table 1: a table showing the symbols

\begin{tabular}{|l|l|}
\hline INPUTS & OUTPUTS \\
\hline Stop pushbutton $=\mathrm{I}_{0.0}$ & Pump no (1) $=\mathrm{Q}_{0.0}$ \\
\hline Start push button $=\mathrm{I}_{0.1}$ & Pump no (2) $=\mathrm{Q}_{0.1}$ \\
\hline Level Liquid Switch1 $=\mathrm{I}_{0.2}$ & Pump no (3) $=\mathrm{Q}_{0.2}$ \\
\hline Level Liquid Switch2 $=\mathrm{I}_{0.3}$ & Pump no (4) $=\mathrm{Q}_{0.3}$ \\
\hline Level Liquid Switch3 $=\mathrm{I}_{0.4}$ & Pump no (5) $=\mathrm{Q}_{0.4}$ \\
\hline Level Liquid Switch4 $=\mathrm{I}_{0.5}$ & Mixer $=\mathrm{Q}_{0.5}$ \\
\hline Level Liquid Switch5 $=\mathrm{I}_{0.6}$ & Mixing Timer $=\mathrm{T}_{37}$ \\
\hline Level Liquid Switch6 $=\mathrm{I}_{0.7}$ & Main Relay $=\mathrm{M}_{0.0}$ \\
\hline Level Liquid Switch7 $=\mathrm{I}_{1.0}$ & \\
\hline
\end{tabular}

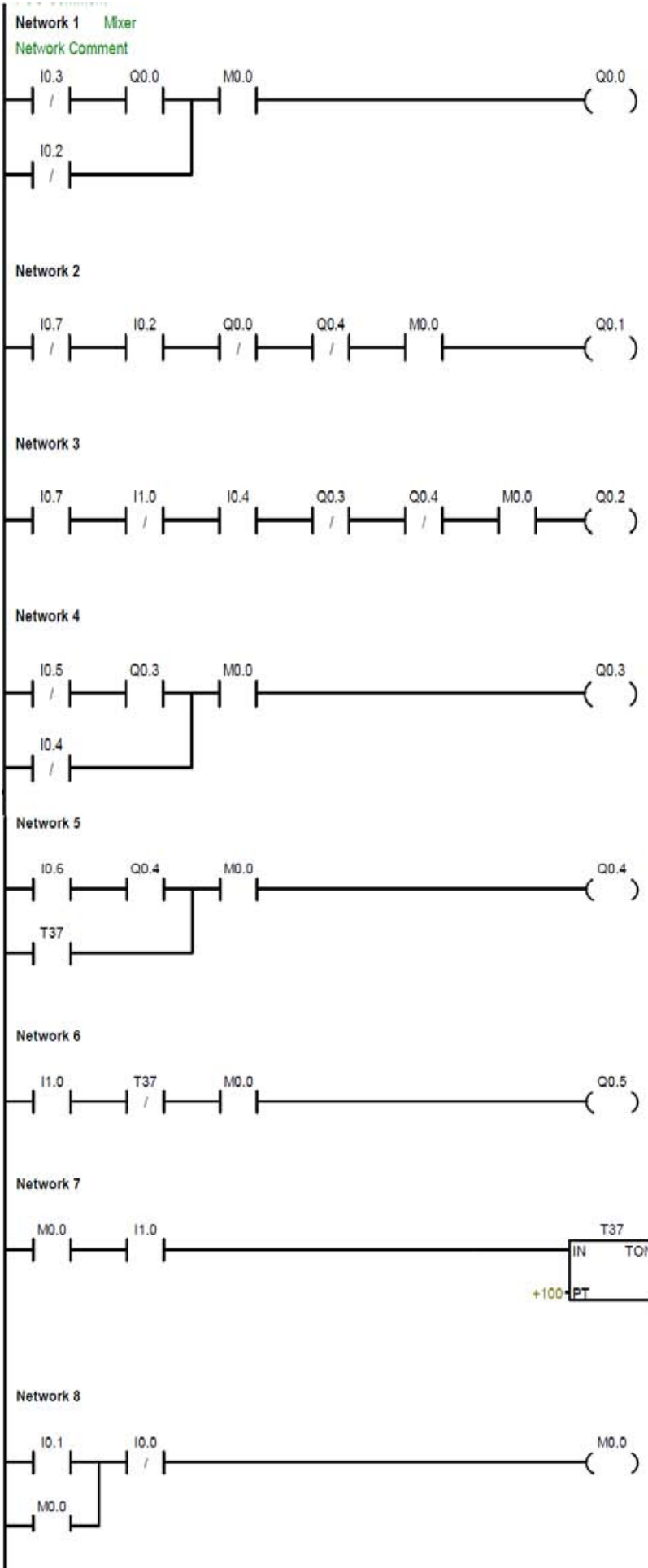

Figure.5: PLC ladder program

\section{Results and discussions}

The use of PLC in automation processes increases reliability and flexibility and also reduces production costs. To obtain accurate industrial electric drive systems, it is necessary to use PLC interfaced with power converters, personal computers and other electric equipment. Many factories use PLC in automation processes to diminish production cost and to increase quality and reliability. This system also used for one of the starting method of three phase slip ring Induction motor this system not only reduces the starting current to a limit, but also develops High starting torque which is required in many of the induction motor applications. This can be applicable to run the lift, by changing the logic in a program and it can also be used for any industrial applications. In the past an engineers had been designing the engineering systems that require a lot of hardware. It is merely impossible to design distance control of the system as more hardware and wiring were needed. With the rise of the technology, programmable logic controller (PLC) have eased the engineering design and lessen materials required, it is because the entire design is implemented in software programming paradigm. This PLC based system requires less hardware compared to any microcontroller or microprocessor based system. Programmable Logic Controllers (PLC) are widely used in industrial control because they are inexpensive, easy to install and very flexible in applications. A PLC interacts with the external world through its inputs and outputs.

\section{Conclusion}

Successful experimental results were obtained from the previously described scheme indicating that the PLC can be used in automated systems with an induction motor. The present work was motivated to develop a scheme to monitor and control by using PLC. Software platform namely Siemens ladder logic programming S7-200 was comprehended, analyzed and implemented. Three phase induction motor was fully automated using a PLC. A complete study on the PLC has imparted a fairly good idea about the industrial automation systems.

\section{References}

[1] M. Fabian and A. Hellgren, "PLC-based implementation of supervisory control for discrete event systems, "in Proc. 37th IEEE Conf. Decision and Control, vol. 3, 1998, pp. 3305-3310.

[2] Ravi Masand, DeepikaJadwani, Prof. S.P Shukla, -Fault Diagnosis Of Induction Motor Using Plc,ll International Journal Of Advanced Research In Electrical, Electronics And Instrumentation Engineering, Vol. 2, Issue 12, December 2013.

[3] J. G. Gilberl, G. R. Diehl, Application of Programmable Logic Controllers to Substation Control and Protection, IEEE Transactions on Power Delivery, Vol. 9, No. 1, January 1994, USA, pp. 384-388

[4] Colak, H. Celik, I. Sefa, and S. Demirbas, "On line protection system for induction motors," Energy 
Convers. Manage.vol. 46, no. 17, pp. 2773- 2786, 2005.

[5] Maria G. Ioannidis" Design and Implementation of PLC-Based Monitoring Control System for Induction Motor" IEEE Transactions on Energy Conversion, Vol. 19, NO. 3, SEPTEMBER 2004469.

[6] W.-F. Chang, Y.-C. Wu and C.-W. Chiu, "Design and Implementation of a Web-Based Distance PLC Laboratory," Proceedings of the 35th Southeastern Symposium on System Theory, Morgantown, 16-18 March 2003, pp. 326-329. doi:10.1109/SSST.2003.1194584 